•研究报告・

\title{
贺兰山甲虫物种丰富度分布格局及其环境解释
}

\author{
杨贵军 ${ }^{*}$ 王 敏 ${ }^{1}$ 杨益春 ${ }^{1}$ 李欣芸 ${ }^{1}$ 王新谱 $^{2}$ \\ 1 (宁夏大学生命科学学院, 银川 750021) \\ 2 (宁夏大学农学院, 银川 750021)
}

摘要: 理解山地物种丰富度分布格局及其成因对于山地生物多样性保护具有重要意义。本文基于贺兰山地区甲虫 31科252属469种的分布信息, 结合相关气候与生境异质性数据, 系统地探讨了贺兰山地区甲虫及 6 个优势科物种 丰富度地理格局及其影响因素。结果表明, 甲虫物种丰富度及科属区系分化强度以贺兰山中段最高, 南段比北段 高, 西坡比东坡高。基于183个栅格内物种分布的二元数据聚类分析, 贺兰山甲虫分布可分为北段强旱生景观甲虫 地理群、中西段半湿生景观甲虫地理群、中东段及南段半旱生景观甲虫地理群3个地理群。咒余分析(RDA)表明年 均温和年均降水量是影响最显著的因子。方差分解结果显示, 水分与能量因子共同解释了全部甲虫物种丰富度 $57.1 \%$ 的空间变异, 单独解释率分别为 $5.9 \%$ 和 $7.1 \%$ 。生境异质性解释了全部甲虫物种丰富度 $35.2 \%$ 的变异, 单独解 释率仅为 $1.8 \%$ 。气候因素与生境异质性对不同优势科物种丰富度的相对影响并不一致。在贺兰山的南段和北段, 生境异质性和水分因子对甲虫物种丰富度影响作用明显。水分和能量因子是贺兰山地区甲虫物种丰富度空间分布 格局的主导因子, 生境异质性有助于提高甲虫物种丰富度。从未解释的比例来分析, 地形和土壤因素可能对贺兰 山甲虫物种丰富度存在重要影响。

关键词: 甲虫; 物种丰富度; 分布格局; 水分; 能量; 生境异质性; 贺兰山

\section{Distribution patterns and environmental interpretation of beetle species richness in Helan Mountain of northern China}

\author{
Guijun Yang ${ }^{1 *}$, Min Wang ${ }^{1}$, Yichun Yang ${ }^{1}$, Xinyun Li $^{1}$, Xinpu Wang ${ }^{2}$ \\ 1 School of Life Sciences, Ningxia University, Yinchuan 750021 \\ 2 School of Agriculture, Ningxia University, Yinchuan 750021
}

\begin{abstract}
Spatial patterns of species richness and mechanism are vital to biodiversity conservation. Based on the distribution of beetles and combined the climate and habitat heterogeneity, we explored the distribution patterns and effect factors of beetle species richness of overall and six dominant families in Helan Mountain of northern China. The results showed that species richness and fauna differentiation intensity of beetles were the highest in the middle of Helan Mountain, the southern section was higher than the northern section, and the western section was higher than the eastern section. After clustering analysis of species distributed in 183 grids, the distribution of beetles could be classified into three groups (xerophilic landscape beetle groups in the northern section, semi-hygric landscape beetle groups in the middle-western section, and semi-xerophytic beetle groups in the middle-east and south section). The mean annual temperature and precipitation were the most significant factors on beetle distribution by analyzing of RDA. Meanwhile, water and energy factors together explained $57.1 \%$ of the spatial variation in overall beetle species richness, only $5.9 \%$ and $7.1 \%$ separately, followed by habitat heterogeneity (35.2\%) and only 1.8\% separately. The relative effect of dominant species richness were inconsistent with climatic and habitat heterogeneity, but water and habitat heterogeneity have significant effect on beetle species richness in southern and northern of Helan Mountain. Water and energy factors dominantly impacted beetle spatial distribution, and habitat heterogeneity increased the species richness. Therefore, we suggested that topographic and soil factors may also have an important influence on beetle species richness in Helan Mountain according to the unexplained proportion.
\end{abstract}


Key words: beetle; species richness; distribution pattern; water factors; energy factors; habitat heterogeneity; Helan Mountain

探索生物多样性的分布格局及其影响机制一 直是宏观生态学和生物地理学的基本问题和研究 热点(Gaston, 2000; Green \& Bohannan, 2006)。基于 栅格法(张荣祖, 2011; 王健铭等, 2019)和行政区划 法(冯建孟和朱有勇, 2010; 张宇和冯刚, 2018)进行 不同尺度生物空间分布格局分析是最简单有效的 方法。生物多样性的空间分布格局是各种生态因子 梯度变化的综合反映, 已有许多学者提出水热动态 假说(O’Brien, 2006)、环境能量假说(Turner, 2004)、 寒冷忍耐假说 (Hawkins, 2001)、种库假说 (Zobel, 1997)以及生境异质性假说(Cox et al, 2016)等来解 释物种多样性空间分布格局的形成机制, 亦有研究 通过分析物种多样性的地理分异格局及其与区系 分化强度之间的关系(冯建孟和朱有勇, 2010), 来解 释物种多样性的地理分布格局及其成因。

关于昆虫地理分布格局及其形成机制的研究, 随着分类研究的深入正逐步开展, 涉及蝗虫(许升 全等, 2004; 白义等, 2006)、蚜虫(乔格侠等, 2003; 郭昆和乔格侠, 2005)、飞闽(李红荣和陈祥盛, 2009)、慓蜡蝉(张争光等, 2018)、蚂蚁(沈梦伟等, 2016)等类群, 并应用分子生物学数据探讨生物地 理学分布(刘殿锋等, 2009; Dong et al, 2018)。基于昆 虫物种的分布信息, 探讨昆虫的多样性及区系分化 格局, 结合地质、地貌、气候及生态环境等特征进 行空间分异研究, 有助于理解昆虫区系起源及其进 化、并为生物多样性保护提供依据。研究表明, 在 较小尺度下, 单一类群昆虫的分布格局主要受某类 因子影响, 例如在山地森林中蚂蚁的丰富度主要受 能量制约(Sanders et al, 2007); 在较大空间尺度, 降 水量、年均温、最冷月温度、生境异质性等均可显 著影响蚂蚁丰富度格局(Gotelli \& Arnett, 2000; 沈 梦伟等, 2016)。影响多类群昆虫分布格局的因子主 要有植物多样性、海拔等生境异质性因素(Schuldt et al, 2010; Shah et al, 2015; 张宇和冯刚, 2018)。

贺兰山地处银川平原与阿拉善高原之间, 是北 温带草原向荒漠过渡的地带, 是我国北方阿拉善鄂尔多斯生物多样性中心的核心区域。贺兰山以西 是腾格里沙漠, 以东是毛乌素沙漠, 以北是乌兰布 和沙漠, 是干旱半干旱地区具有代表性的自然综合
体和较完整的自然生态系统, 其孤立于荒漠之中, 是趋于中生生境的“岛屿”, 具有带谱比较完整的山 地植被垂直带结构和丰富的生物资源(王小明, 2011; 梁存柱等, 2012)。关于该地区昆虫区系的研究集中 于近些年的综合考察, 其中记录甲虫30科211属355 种(王新谱和杨贵军, 2010; 白晓拴等, 2013)。甲虫 是昆虫纲中最大的类群, 起源于三叠纪, 其生态功 能十分重要(Diniz-Filho et al, 2010), 其分类信息及 地理分布信息的缺乏, 是限制进行生物地理分布格 局研究的主要原因。作者在近些年考察的基础上, 陆续采集并整理鉴定该地区甲虫31科252属469种, 并详细记录了物种分布信息(附录1)。本文依据贺兰 山甲虫的分布信息及其相关的环境数据，以期探究 以下问题: (1)研究区甲虫物种丰富度及科属区系分 化强度在水平方向上存在怎样的分布格局; (2)研究 区甲虫物种丰富度的主导因素是什么, 不同优势科 物种多样性的影响因素是否存在差异。

\section{研究区域与方法}

\section{1 研究区概况}

贺兰山位于 $105^{\circ} 41^{\prime}-106^{\circ} 41^{\prime} \mathrm{E}, 38^{\circ} 13^{\prime}-39^{\circ} 30^{\prime} \mathrm{N}$, 山体呈西南-东北走向, 长约 $270 \mathrm{~km}$, 宽约 $20-40 \mathrm{~km}$, 山体东坡地势平缓, 西坡相对陡峭。山地主体海拔 2,000-3,000 m, 最高峰鄂博疮㾂海拔3,556 m。该区 域属中温带干旱气候区, 是典型的大陆性气候, 且 山地气候明显。年均气温为 $-0.8^{\circ} \mathrm{C}$, 年降水量为 200-400 mm。受气候、土壤、地势等因素影响, 贺 兰山保护区植被具有明显的垂直分异特征(王小明, 2011; 梁存柱等, 2012)。

\section{2 物种分布数据}

昆虫的物种分布信息主要通过以下途径获取: (1)作者2007-2018年的实地采集; (2)宁夏农林科学 院昆虫馆保存标本；(3) 2007-2011年贺兰山自然保 护区综合科学考察中的甲虫标本信息(王新谱和杨 贵军, 2010; 白晓拴等, 2013)。共获取标本40,000余 份, 隶属于31科252属469种, 其中步甲科(31属97 种)、拟步甲科(24属63种)、金龟科(26属49种)、天 牛科(31属42种)、象甲科(27属34种)和㼼虫科(16属 27 种)数量较多。 
利用ArcGIS结合贺兰山数字高程模型(DEM), 将贺兰山区域按照 $5 \mathrm{~km} \times 5 \mathrm{~km}$ 进行栅格划分(图1), 栅格内面积不足 $1 / 4$ 的忽略不计，面积介于 $1 / 4-1 / 2$ 的合并至相邻栅格，总计获得有效柱格183个。将贺 兰山甲虫采集坐标信息在GIS叠加, 统计每个栅格 内的昆虫分布信息(贾龙, 2014)。

\section{3 环境数据}

\subsection{1 气候数据}

选取影响物种丰富度分布格局的7个气候指标, 包括3个水分因子, 即年均降水量(mean annual precipitation, MAP)、年均实际蒸散量(mean annual actual evapotranspiration, AET)、年均潜在蒸散量(mean annual potential evapotranspiration, PET); 4 个能量因 子, 即年均温(mean annual temperature, MAT)、最冷 月均温(mean temperature of coldest month, MTCM)、 最热月均温(mean temperature of warmest month, MT$\mathrm{WM}$ )和年均太阳辐射(mean annual solar radiation,

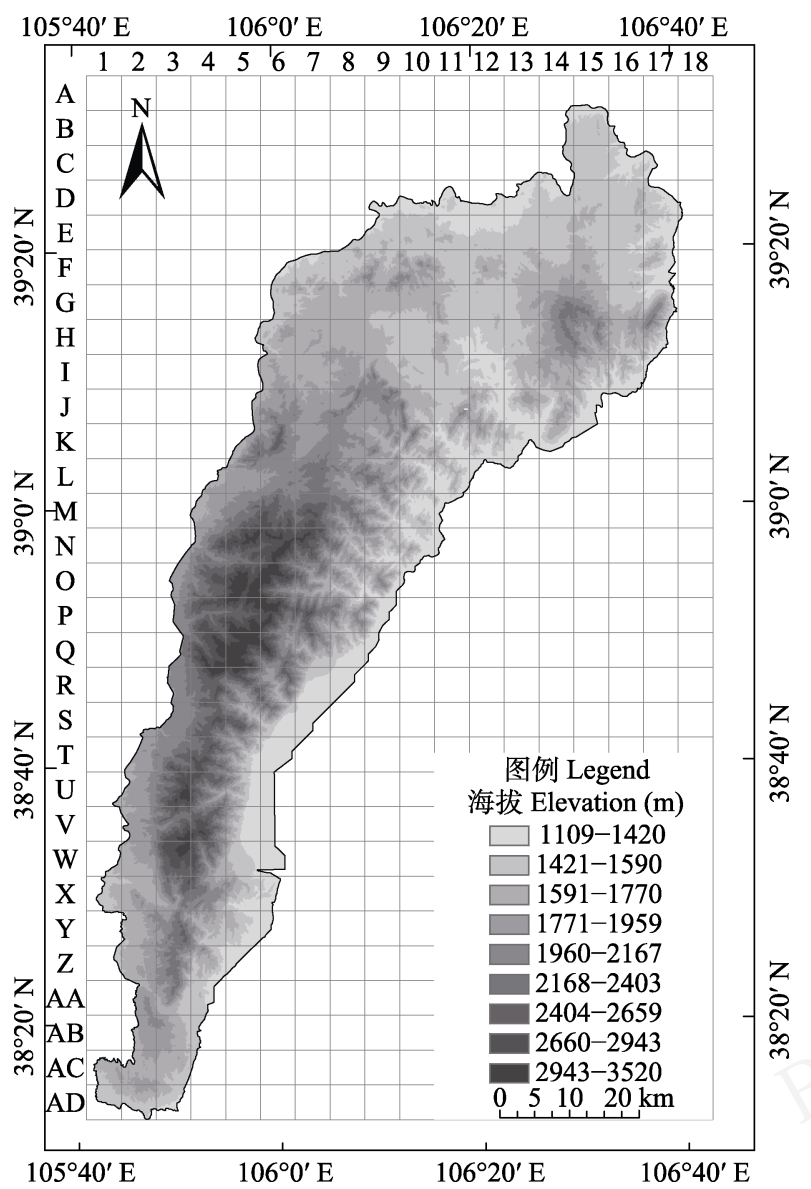

图1 贺兰山地区甲虫分布格局研究的地理单元

Fig. 1 Grids for study on geographic distribution patterns of beetle in the Helan Mountain area
MASR)。其中，PET和AET数据来源于国际农业研究 组织提供的 $1 \mathrm{~km} \times 1 \mathrm{~km}$ 分辨率的全球干旱指数和 潜在蒸散气候数据库(http://www.cgiarcsi.org), 其余 气候变量数据来自世界气候数据网(http://www. worldclim.org) $1 \mathrm{~km} \times 1 \mathrm{~km}$ 分辨率的气候数据, 以 上数据均为1970-2000年的平均值。

\subsection{2 生境异质性数据}

用单位㹪格内的海拔高差(altitude difference, $\mathrm{AD}$ )、植被类型数(植被多样性, vegetation diversity, VD)和植被归一化指数(normalized difference vegetation index, NDVI)表征生境异质性。海拔高差，即 各栅格内最高海拔与最低海拔之差, 根据贺兰山 数字高程模型(DEM)计算得到。将等面积栅格系统 与贺兰山植被 $1: 250000$ 植被图(梁存柱等, 2012)叠 加, 统计每个网格内的植被类型数(VD)。植被归一化 指数(NDVI)获取自地理国情监测云平台(http://www. dsac.cn) $30 \mathrm{~m} \times 30 \mathrm{~m}$ 分辨率的数据(2000-2016)。

1.4 物种丰富度、多样性、区系分化强度和相似性 分析

(1)以每个栅格内昆虫物种数表征物种丰富度。 采用 $G-F$ 指数(蒋志刚和纪力强, 1999 ) 衡量属 $\left(D_{\mathrm{G}}\right)$ 与 科 $\left(D_{\mathrm{F}}\right)$ 水平上的物种多样性变化, $D_{\mathrm{G}}$ 是 $D_{\mathrm{F}}$ 的次一级 分类阶元多样性，所以 $D_{\mathrm{G}} \leq D_{\mathrm{F}}$; 非单种科越多，则 $D_{\mathrm{G}} / D_{\mathrm{F}}$ 比值越小, $G-F$ 指数越高, 计算公式如下:

$$
\begin{aligned}
& D_{\mathrm{G}-\mathrm{F}}=1-D_{\mathrm{G}} / D_{\mathrm{F}} \\
& D_{\mathrm{F}}=\Sigma D_{\mathrm{FK}}, D_{\mathrm{FK}}=-\Sigma p_{\mathrm{i}} \ln p_{\mathrm{i}} \\
& D_{\mathrm{G}}=-\Sigma q_{\mathrm{j}} \mathrm{ln} q_{\mathrm{j}}
\end{aligned}
$$

式中, $p_{\mathrm{i}}=S_{\mathrm{ki}} / S_{\mathrm{k}}, S_{\mathrm{k}}$ 为群落中 $k$ 科的物种数, $S_{\mathrm{ki}}$ 为群落 中 $k$ 科 $i$ 属的物种数。 $q_{\mathrm{j}}=S_{\mathrm{j}} / S, S$ 为群落物种总数, $S_{\mathrm{j}}$ 为 群落中 $j$ 属的物种数。

(2)属 $\left(D_{\mathrm{g}}\right)$ 和科 $\left(D_{\mathrm{f}}\right)$ 的区系分化强度计算公式如下:

$$
D_{\mathrm{g}}=N_{\mathrm{sp}} / N_{\mathrm{g}}
$$

$D_{\mathrm{f}}=N_{\mathrm{g}} / N_{\mathrm{f}}$

其中, $N_{\mathrm{sp}} 、 N_{\mathrm{g}}$ 和 $N_{\mathrm{f}}$ 分别为栅格内的物种数、属数和 科数(冯建孟和朱有勇, 2010)。

(3)基于栅格单元中的物种分布数据(二元数据, 有分布为 1 , 无分布为 0$)$, 运用 Jaccard系数 $\left(C_{\mathrm{j}}\right)$ 计算 相似性, 采用非加权组平均法(unweighted pair-group method with arithmetic means, UPGMA)对地理单元 进行层次聚类分析。 $C_{\mathrm{j}}=c /(a+b-c)$, 式中 $C_{\mathrm{j}}$ 是两个 研究地理单元间的相似性系数, $a$ 和 $b$ 分别是两单元的 物种数, $c$ 是两个单元的共有物种数(Jaccard, 1912)。 


\section{5 数据分析}

运用Origin 9.0软件, 采用一元非线性回归方法 的高斯函数模型, 分析甲虫物种丰富度和区系分化 强度在南北、东西方向上的变化, 以阐明物种丰富 度的空间分布格局。用SPSS 23.0软件对区域内物种 丰富度与气候因素、生境异质性进行一元线性回归 分析，确定物种丰富度与不同环境因素的关系。

利用物种丰富度与环境变量(水分因子、能量因 子及生境异质性)做圥余分析(RDA), 并通过方差分 解来探讨水分、能量和生境异质性3组变量对物种 丰富度的独立解释率以及共同解释率。冗余分析 (RDA)和方差分解用Canoco 5.12软件, 用前向选择 (forward selection)分析各种环境因子对甲虫分布及 多样性的贡献率和显著性, 分析前对地表甲虫类群 个体数量及环境因子数据进行 $\lg (x+1)$ 转换。

\section{2 结果}

\section{1 甲虫物种丰富度及科属区系分化强度的空间} 分布格局

甲虫物种丰富度在经度和纬度方向均呈现明

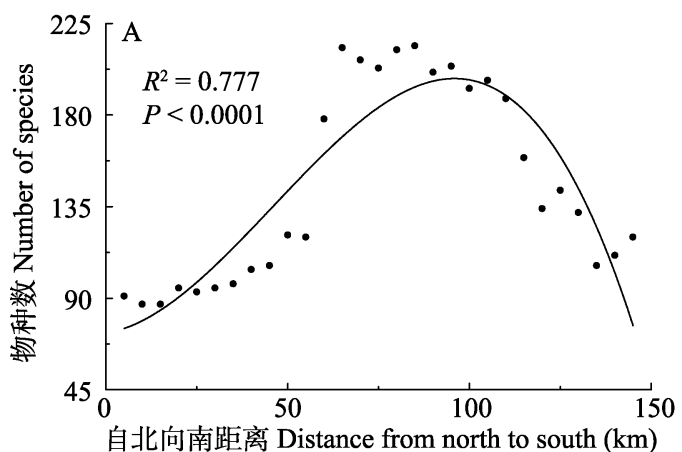

显的不对称单峰曲线变化趋势，在自北向南65-125 $\mathrm{km}$ 范围较高, 在此范围的南、北段减少，而且南段 比北段略高(图2A)。沿经度方向，物种丰富度在自 西向东15-30 km范围较高, 西部显著高于东部, 东 部呈显著的降低趋势(图2B)。因此，物种丰富度以 贺兰山中段(自北段插旗口沟至南段小口子沟)较高, 西坡较东麓高。

自北向南方向上，科和属区系分化强度呈现明 显的单峰曲线 $(P<0.0001)$ (图3)。属的区系分化强度 在自北向南60-110 km范围较高(自北段插旗口沟至 南段小口子沟)，在1.68-1.72之间，此范围的南北两 端逐渐下降(图3A)。科的分化强度在自北向南55-85 $\mathrm{km}$ 范围较高，在4.80-5.42之间，在自北段插旗口沟 至南段甘沟范围达到峰值(图3B)。

自西向东方向上(图4)，属和科的区系分化强 度呈明显的不对称单峰曲线。在属的水平上，分化 强度在1.53-1.90之间，峰值(1.90)出现在自西向东 10-20 km范围内，即最高值范围在西坡(图4A); 科 的水平上，区系分化强度在4.06-6.06之间，最高峰 (6.06)出现在自西向东10-30 km范围内, 最高值也

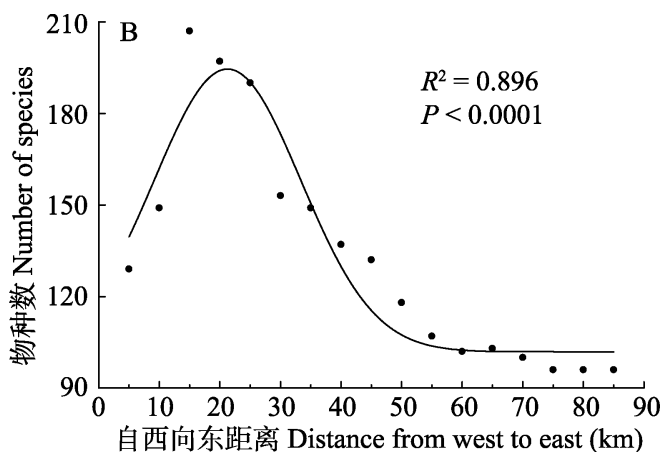

图2 贺兰山甲虫物种丰富度分布格局

Fig. 2 The distribution patterns of beetle species richness in Helan Mountain

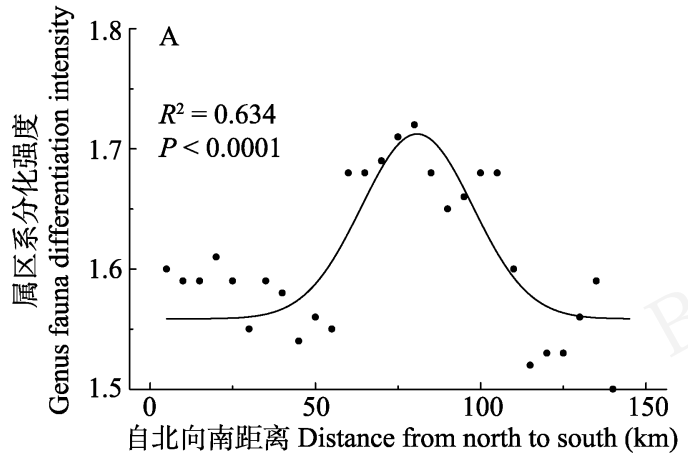

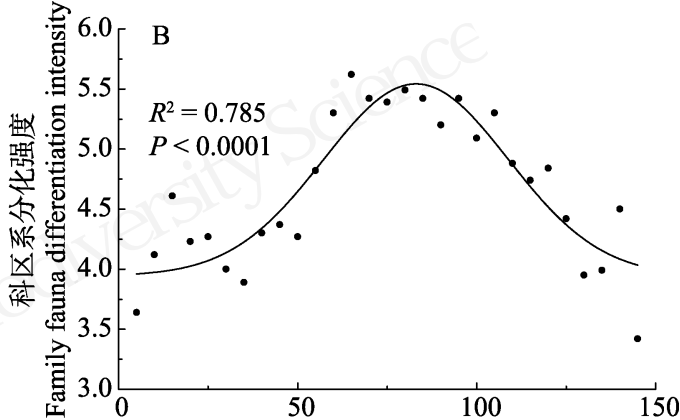

自北向南距离 Distance from north to south $(\mathrm{km})$

图3 贺兰山甲虫属、科的区系分化在南北方向变化

Fig. 3 The shift of fauna differentiation of the genus and the family of beetles from north to south in Helan Mountain 

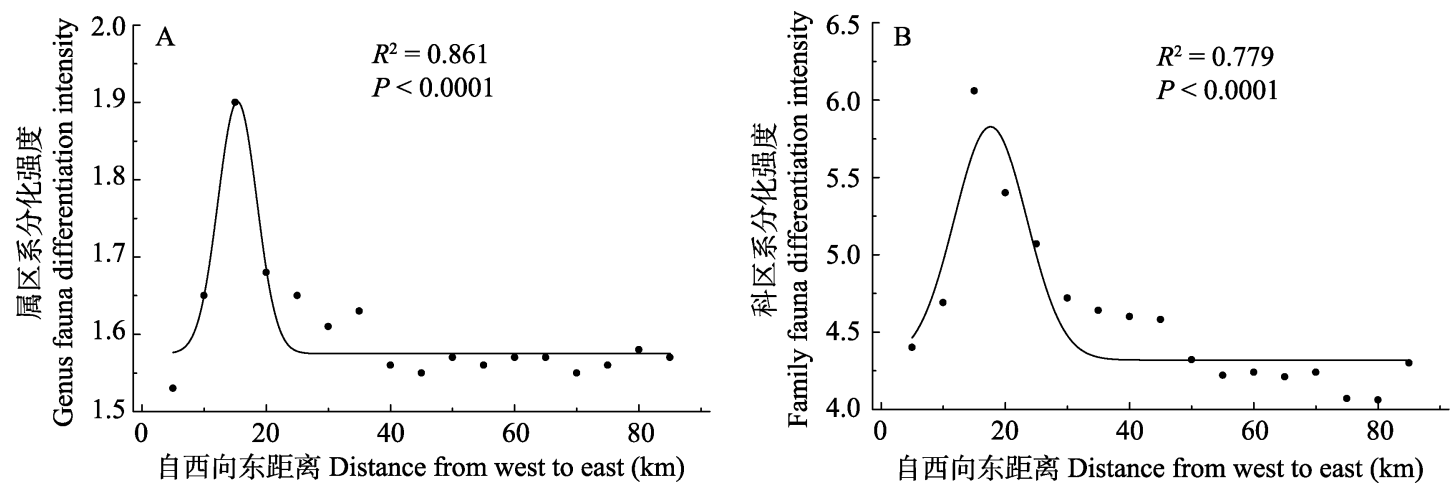

图4 贺兰山甲虫属、科的区系分化在东西方向变化

Fig. 4 The shift of fauna differentiation of the genus and the family of beetles from west to east in Helan Mountain

集中在西坡(图4B), 但属的分化强度的峰值范围 $\left(105.85^{\circ}-105.95^{\circ} \mathrm{E}\right)$ 比科的分化强度的峰值范围 $\left(105.85^{\circ}-106.05^{\circ} \mathrm{E}\right)$ 窄。

总体上，贺兰山东麓甲虫区系分化强度低于西 坡, 东坡 $106.05^{\circ} \mathrm{E}$ 以东范围, 属和科的分化强度基 本呈水平变化。因此, 区系分化强度较大区域主要 集中在地形复杂、物种多样性丰富的中段区域，而 在北段与南段, 甲虫属和科的区系分化能力则相对 较弱。

\section{2 甲虫分布格局的相似性聚类分析}

基于 183 个地理单元中 469 种昆虫的二元分布 数据, 采用Jaccard相似性系数计算相似性矩阵, 运 用非加权组平均法(UPGMA), 对地理单元进行聚 类分析。结果表明, 在Jaccard相似性系数为 0.36 时, 贺兰山183个地理单元的甲虫聚为3个地理群(图5), 即北段强旱生景观甲虫地理群(I), 界线大致为汝箕 沟(东坡)-油门沟(西坡)一线以北; 中西段半湿生景 观甲虫地理群(II), 界线大致为汝箕沟(东坡)-油门 沟(西坡)一线以南, 榆树沟(西坡-东坡)以北海拔 $1,800 \mathrm{~m}$ 以上; 中东段及南段半旱生景观甲虫地理 群(III), 界线大致为中段东部汝箕沟(东坡)和南段 榆树沟以南海拔1,200-1,800 m范围的半旱生景观 甲虫地理群。

不同地理单元群甲虫多样性比较结果见表1, 地理群III的科、属数最多, 地理群II的物种丰富度最 高，从 $D_{\mathrm{G}} 、 D_{\mathrm{F}}$ 指数看，中东段及南段半旱生景观甲 虫地理群(III)均最高, 其次是中西段半湿生景观甲 虫地理群(II), 说明贺兰山中段和南段种类比较丰 富。G-F指数方面, 3 个地理群都非常接近, 可能是因 为同属于一个山体, 地理位置相近, 总体上地理群

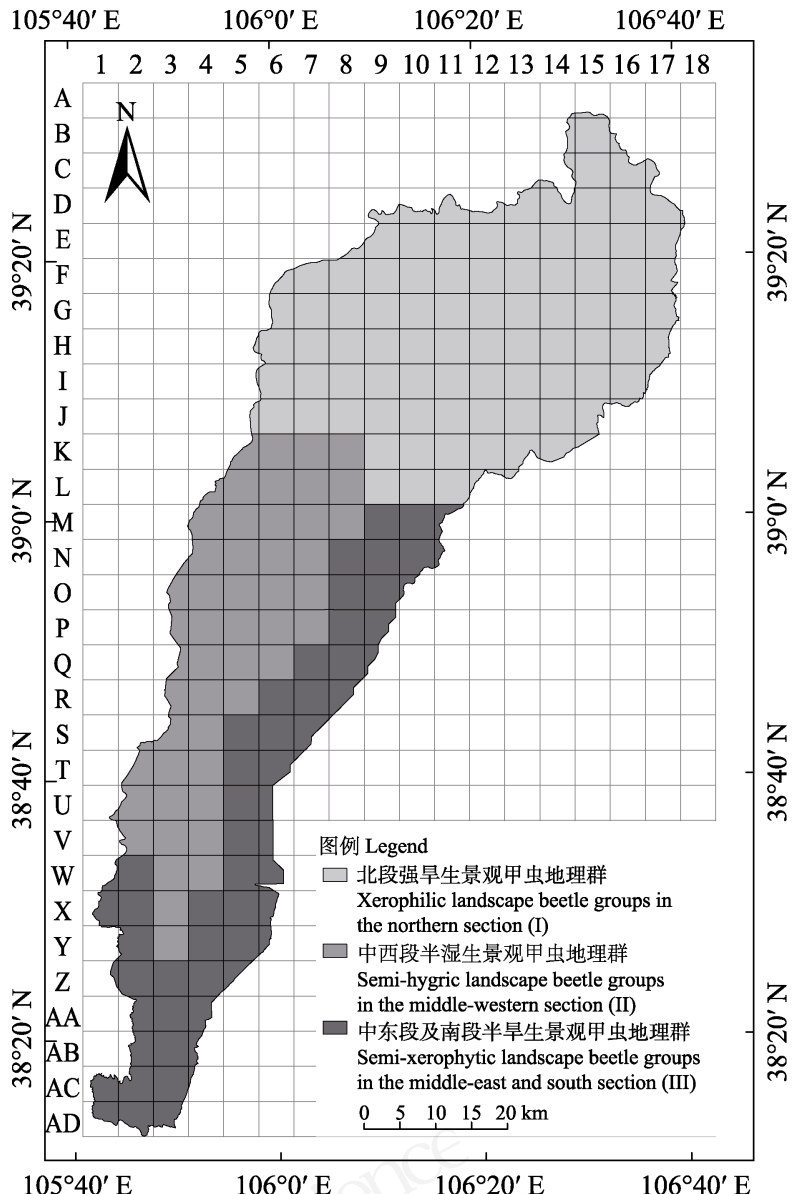

图5 贺兰山甲虫地理单元划分

Fig. 5 The geographical division of beetle in Helan Mountain

II和III大于地理群I，说明贺兰山中段和南段甲虫非 单种科最多，而北段区域最少。属和科的区系分化 强度均以地理群II为最高。

\section{3 不同环境因子与甲虫物种丰富度及区系分化} 强度的关系

线性回归分析结果显示(表2), 贺兰山甲虫物 
表1 贺兰山不同地理单元甲虫群落多样性比较

Table 1 Comparison of beetle diversity in different geographical units in Helan Mountain

\begin{tabular}{|c|c|c|c|c|c|c|c|c|}
\hline & $\begin{array}{l}\text { 科数 } \\
\text { No. of } \\
\text { family }\end{array}$ & $\begin{array}{l}\text { 属数 } \\
\text { No. of } \\
\text { genus }\end{array}$ & $\begin{array}{l}\text { 种数 } \\
\text { No. of } \\
\text { species }\end{array}$ & $\begin{array}{l}G \text { 指数 } \\
\left(D_{\mathrm{G}}\right)\end{array}$ & $\begin{array}{l}F \text { 指数 } \\
\left(D_{\mathrm{F}}\right)\end{array}$ & $\begin{array}{l}G-F \text { 指数 } \\
\left(D_{\mathrm{G}-\mathrm{F}}\right)\end{array}$ & $\begin{array}{l}\text { 属区系分化强度 } \\
\text { Genus fauna } \\
\text { differentiation } \\
\text { intensity }\left(D_{\mathrm{g}}\right)\end{array}$ & $\begin{array}{l}\text { 科区系分化强度 } \\
\text { Family fauna } \\
\text { differentiation } \\
\text { intensity }\left(D_{\mathrm{f}}\right)\end{array}$ \\
\hline $\begin{array}{l}\text { 北段强早生景观甲虫地理群 } \\
\text { Xerophilic landscape beetle groups in the } \\
\text { northern section (I) }\end{array}$ & 26 & 145 & 250 & 4.71 & 26.80 & 0.824 & 1.57 & 3.19 \\
\hline $\begin{array}{l}\text { 中西段半湿生景观甲虫地理群 } \\
\text { Semi-hyygic landscape beetle groups } \\
\text { in the middle-western section (II) }\end{array}$ & 29 & 218 & 419 & 5.03 & 35.35 & 0.858 & 1.73 & 4.29 \\
\hline $\begin{array}{l}\text { 中东段及南段半旱生景观甲虫地理群 } \\
\text { Semi-xerophytic landscape beetle groups in } \\
\text { the middle-east and south section (III) }\end{array}$ & 30 & 222 & 378 & 5.14 & 37.49 & 0.863 & 1.53 & 3.79 \\
\hline
\end{tabular}

\section{表2 贺兰山甲虫物种丰富度和区系分化强度与环境因子的一元回归相关系数}

Table 2 The correlation coefficients between beetle species richness, fauna differentiation intensity and environmental factors in Helan Mountain

\begin{tabular}{llll}
\hline 环境因子 & $\begin{array}{l}\text { 物种丰富度 } \\
\text { Species richness } \\
\left(N_{\mathrm{sp}}\right)\end{array}$ & $\begin{array}{l}\text { 属区系分化强度 } \\
\text { Genus fauna differentiation } \\
\text { intensity }\left(D_{\mathrm{g}}\right)\end{array}$ & $\begin{array}{l}\text { 科区系分化强度 } \\
\text { Family fauna differentiation } \\
\text { intensity }\left(D_{\mathrm{f}}\right)\end{array}$ \\
\hline 海拔高差 Altitude difference (AD) & $0.54^{*}$ & $0.27^{*}$ & $0.46^{*}$ \\
植被类型数 Vegetation diversity (VD) & $0.55^{*}$ & $0.49^{*}$ & $0.27^{*}$ \\
植被归一化指数 Normalized difference vegetation index (NDVI) & $0.56^{*}$ & $0.41^{*}$ & $0.60^{*}$ \\
年均降水量 Mean annual precipitation (MAP) & $0.61^{*}$ & $0.34^{*}$ & $0.62^{*}$ \\
年均潜在蒸散量 Mean annual potential evapotranspiration (PET) & $0.31^{*}$ & $0.50^{*}$ & $0.25^{*}$ \\
年均实际蒸散量 Mean annual actual evapotranspiration (AET) & $0.49^{*}$ & $0.39^{*}$ & $0.36^{*}$ \\
年均温 Mean annual temperature (MAT) & $-0.34^{*}$ & $-0.58^{*}$ & $-0.44^{*}$ \\
最冷月均温 Mean temperature of coldest month (MTCM) & $-0.26^{*}$ & $-0.51^{*}$ & $-0.19^{*}$ \\
最热月均温 Mean temperature of warmest month (MTWM) & $-0.41^{*}$ & $-0.58^{*}$ & $-0.34^{*}$ \\
年均太阳辐射 Mean annual solar radiation (MASR) & $-0.56^{*}$ & $-0.32^{*}$ & $-0.57^{*}$
\end{tabular}

$* P<0.001$

\section{表3 环境因子对甲虫物种丰富度分布的相对贡献}

Table 3 The relative contribution of environmental factors for distribution of beetle species richness

\begin{tabular}{|c|c|c|c|c|}
\hline \multirow{2}{*}{$\begin{array}{l}\text { 环境因子 } \\
\text { Environmental factor }\end{array}$} & 解释率 & 贡献率 & $F$ & $P$ \\
\hline & \multicolumn{4}{|c|}{ Percentage of variance explained (\%) Contribution (\%) } \\
\hline 年均温 Mean annual temperature (MAT) & 34.8 & 57.0 & 96.6 & 0.002 \\
\hline 年均降水量 Mean annual precipitation (MAP) & 9.9 & 16.2 & 32.1 & 0.002 \\
\hline 最冷月均温 Mean temperature of coldest month (MTCM) & 3.8 & 6.1 & 13 & 0.002 \\
\hline 年均潜在蒸散量 Mean annual potential evapotranspiration (PET) & 3.6 & 5.9 & 13.3 & 0.002 \\
\hline 海拔高差 Altitude difference (AD) & 3.0 & 4.9 & 11.7 & 0.002 \\
\hline 最热月均温 Mean temperature of warmest month (MTWM) & 2.8 & 4.5 & 11.6 & 0.002 \\
\hline 年均实际蒸散量 Mean annual actual evapotranspiration (AET) & 1.5 & 2.5 & 6.5 & 0.002 \\
\hline 年均太阳辐射 Mean annual solar radiation (MASR) & 1.0 & 1.6 & 4.2 & 0.002 \\
\hline 植被归一化指数 Normalized difference vegetation index (NDVI) & 0.6 & 0.9 & 2.5 & 0.002 \\
\hline 植被类型数 Vegetation diversity (VD) & 0.3 & 0.5 & 1.4 & 0.048 \\
\hline
\end{tabular}

种丰富度和区系分化强度与全部水分因子呈极显 著的正相关 $(P<0.001)$, 而与全部能量因子呈极显
著的负相关 $(P<0.001)$ 。生境异质性可明显提高甲 虫物种丰富度及科、属区系分化强度 $(P<0.001)$ 。 


\section{4 水分、热量与生境异质性对甲虫物种丰富度的 相对影响}

运用Canoco软件对甲虫物种丰富度与环境因 子进行圥余分析(RDA), 前项选择结果表明(表3), 年均温(34.8\%, $P<0.01)$ 、年均降水量 $(9.9 \%, P<$ $0.01)$ 、海拔高差 $(3.0 \%, P<0.01)$ 分别是能量因子、水 分因子和生境异质性因子中独立解释率最高的因子。

圥余分析和方差分解分析的结果显示(图6), 水分、能量和生境异质性因子共同解释了全部物种 丰富度 $58.9 \%$ 的变异, 其中水分和能量共同解释率 为 $57.1 \%$, 单独解释率分别为 $5.9 \%$ 和 $7.1 \%$ 。生境异 质性可以解释物种丰富度 $35.2 \%$ 的变异, 单独解释 率仅为 $1.8 \%$ 。水分、能量和生境异质性因子三者公 共解释率为 $25.0 \%$ 。

水分、能量与生境异质性对不同优势科类群丰 富度解释率不同。水分因子对拟步甲科丰富度具有 最大解释率(48.7\%), 能量因子对天牛科丰富度有 着最大解释率(52.6\%), 生境异质性对所有科的独 立解释率均低于水分、能量因子的影响, 其中对天 牛科的解释率最大 $(41.5 \%)$ 。水分、能量和生境异质 性三类因子中任意两个因子的共同影响均表现为 对天牛科丰富度具有最大解释率。

依据图5贺兰山甲虫地理群划分结果, 分析不 同地理群水分、能量和生境异质性因子对物种丰富 度的影响(图7), 水分、能量和生境异质性因子共计
分别解释了地理群I、II和III物种丰富度 $47.2 \%$ 、 $39.9 \%$ 和 $48.6 \%$ 的变异。水分因子分别解释了地理群 I、II和III甲虫物种丰富度 $33.5 \%$ 、28.9\%和 $30.2 \%$ 的 变异, 对地理群 $\mathrm{I}$ 物种丰富度解释率最大。对于地理 群II和 III, 能量因子解释率最大，分别为 $30.7 \%$ 和 $31.2 \%$ 。生境异质性单独解释率均最低, 对地理群III 物种丰富度解释率最大(21.1\%), 单独解释率为 $9.7 \%$ 。

\section{3 讨论}

\section{1 贺兰山甲虫物种丰富度及区系分化强度格局}

贺兰山是我国北方阿拉善-鄂尔多斯生物多样 性中心的核心区域，是北温带草原向荒漠过渡的地 带，该区域生态环境脆弱，但孕育了较为丰富的生 物多样性, 植物群落物种丰富度存在着显著的空间 异质性，即中段以森林和中生灌从为主，南、北段 荒漠化程度较高, 东坡比西坡植被覆盖度低(王炜 等, 2004; 梁存柱等, 2012)。本研究结果表明, 贺兰 山已知的31科252属469种甲虫也存在着明显的地 理分布差异，物种丰富度以贺兰山中段(自北段插 旗口沟至南段小口子沟)较高, 西坡较东麓高, 说明 贺兰山中段地区甲虫物种多样性最为丰富, 值得重 点保护和关注，而其他地区则相对贫乏。区系分化 强度较大区域主要集中在物种多样性丰富的中段 区域及西坡，而在北段与南段，甲虫属和科的区系 分化能力则相对较弱，说明贺兰山地区甲虫物种丰
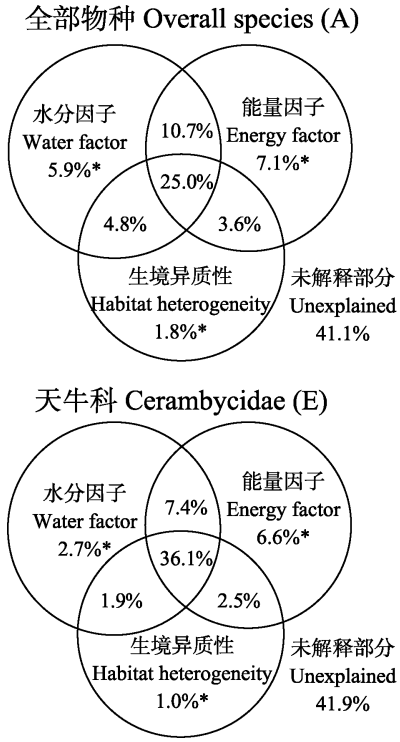

步甲科 Carabidae (B)
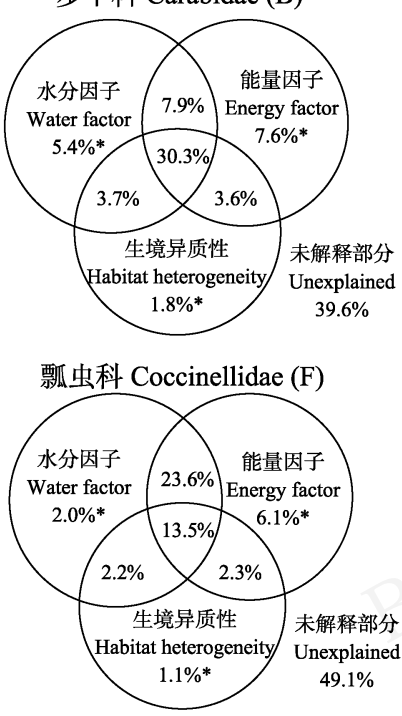

拟步甲科 Tenebrionidae (C)
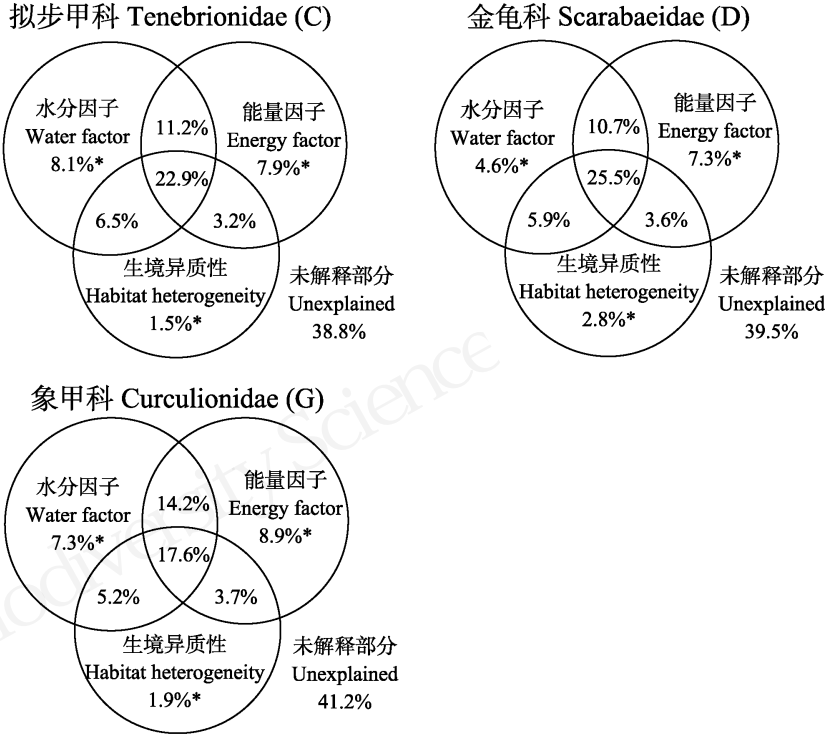

图6 水分、能量与生境异质性因子对甲虫全部物种和优势科丰富度分布的影响(A-G)。*P< 0.001 。

Fig. 6 Relative influence of water, energy and habitat heterogeneity on distribution of beetle species richness of overall and dominant family. ${ }^{*} P<0.001$. 


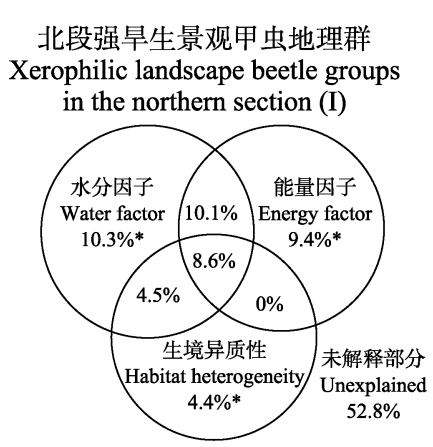

中西段半湿生景观甲虫地理群

Semi-hygric landscape beetle groups in the middle-western section (II)

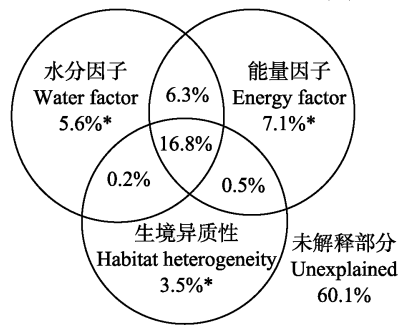

中东段及南段半旱生景观甲虫地理群

Semi-xerophytic landscape beetle groups in the middle-east and south section (III)

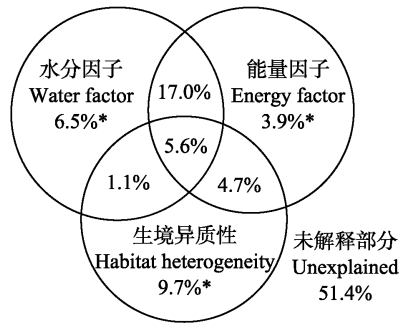

图7 水分、能量与生境异质性因子对不同地理单元甲虫丰富度分布格局的解释。 $* \boldsymbol{P}<\mathbf{0 . 0 0 1}$ 。

Fig. 7 Relative influence of water, energy and habitat heterogeneity on distribution of beetle species richness in different geographical units. $* P<0.001$.

富度与区系分化强度之间存在密切的联系。甲虫物 种丰富度和区系分化与植被空间分异有较好的对 应关系, 说明植物多样性增加有助于甲虫多样性的 提高，为甲虫提供了更丰富的生态空间及食物资源 (Zhang et al, 2016)。

属的分化通常被认为是近现代历史地质和环 境的表现, 科的分化被认为表征比较久远的地质历 史(李果等, 2009; 梁存柱等, 2012)。目前关于贺兰 山昆虫的起源未见报道, 但植物与昆虫是协同进化 的, 植物的区系变化、地质历史、气候变迁特征等 均在一定程度上反映本地甲虫区系的起源历史非 常悠久(王新谱和杨贵军, 2010)。研究表明贺兰山是 滨太平洋和特提斯-喜马拉雅构造域联合作用的结 果, 贺兰山经历了 3 次较大隆升, 致使大陆性气候 增强, 山地垂直植被带于第三纪末形成, 中段抬升 最高, 在南北方向和东西方向上具有不同的水热条 件组合以及植被组成(赵红格等, 2007; 王小明, 2011)。生境异质性的增强为甲虫分布创造了条件, 地形相对复杂的中段地区甲虫区系强烈分化, 其物 种丰富度显著增加, 南、北段则较低, 尤其是北段 整体维持在较低水平。基于甲虫分布栅格的聚类分 析表明, 中段的地理群II的物种丰富度、属和科的区 系分化强度最大(表1), 推测是由于该区域海拔高差 最大, 由此引起的生境异质性最大, 昆虫物种分化 明显。因此, 该区域是甲虫物种多样性保护的核心 区域。地理群III具有较高的科、属多样性, G-F指数 较大, 可能是由于该区域有银川平原及湿地昆虫种 类的渗透。

\section{2 气候和生境异质性对甲虫物种丰富度分布格 局的相对影响}

大尺度上的水热条件被认为是地带性植被与
生物物种多样性地理分布格局形成的决定性因素。 贺兰山地处银川平原和阿拉善高原之间, 位于中温 带干旱气候区, 是典型的大陆性气候, 山体陡峭、 地形复杂, 山地气候明显。贺兰山三面环绕的沙漠 景观对该山体水热空间分布有着强烈影响。因此, 较小尺度下, 山地生物多样性空间分布格局受自身 地形地貌及周围景观引起的水热条件的影响。本研 究表明, 甲虫物种丰富度与水分因子呈显著正相关, 与能量因子显著负相关, 说明能量对于地处干旱区 的贺兰山甲虫多样性更多是抑制因素, 这可能是贺 兰山地区日照强, 蒸发量大, 降低了昆虫直接或间 接对水资源的利用(王健铭等, 2019)。方差分解结果 显示, 水分和能量对甲虫全部物种丰富度变异的总 解释率相当, 共同解释了贺兰山全部甲虫物种丰富 度 $57.1 \%$ 的变异, 且它们均存在显著的单独解释率 (图6), 说明它们共同决定了贺兰山地区甲虫物种丰 富度地理格局。冗余分析(RDA)方差分解结果显示 (图7), 水分因子对地理群I和III甲虫物种丰富度影 响大于能量因子, 地理群II中能量因子影响大于水 分因子。很多研究证明生境异质性可以为更多物种 提供更多样化的资源与生态位(Chen et al, 2011)。本 研究显示, 贺兰山甲虫物种丰富度均与生境异质性 存在显著的正相关, 这说明高生境异质性可以为甲 虫物种共存与多样性维持提供更多的机会。但是, 生境异质性对全部物种单独解释率明显低于水分 和能量因子。在地理群III中, 生境异质性对全部物 种的解释率明显提高, 和水分因子成为贺兰山北 段、南段甲虫物种丰富度的限制性因子。

水分、能量与生境异质性对不同优势科物种丰 富度影响并不一致, 这可能是由于进化历史、食性、 扩散能力与生活史策略的差异造成的(王志恒等, 
2009)。本研究表明(图6), 水分因子对拟步甲科丰富 度具有最大解释率, 该科昆虫在贺兰山的分布以海 拔2,000 $\mathrm{m}$ 以下的干旱生境为主, 说明水分因子是 干旱地区拟步甲昆虫物种多样性维持最为关键的 限制因子。步甲科广泛分布于各种生境，且在中高 海拔趋于向中生湿润的环境聚集, 能量因子的作用 大于水分因子。天牛科和漂虫科等其他科昆虫趋向 分布于植被郁闭度较高的中生环境, 物种丰富度受 能量因子的作用略大。生境异质性对所有科的独立 解释率均低于水分、能量因子的单独影响, 在各自 的模型中, 占比最高的是天牛科, 最低的是瓢虫科, 可能是由于漂虫科几乎全部是肉食性, 生境异质性 对该科的影响比对植食性的天牛科昆虫要小。

综上可见，水分和能量因子是贺兰山地区甲虫 物种丰富度空间分布格局的主导因子，生境异质性 有助于提高甲虫物种丰富度, 而在贺兰山的南、北 段, 生境异质性和水分因子作用明显。在本研究中, 水分、能量和生境异质性并没有完全解释对贺兰山 甲虫全部物种和优势科种类丰富度格局的所有变 异。山地是具有一定的海拔高度、相对高度和坡度 的生态复合系统，地形通过地貌过程控制了光、热、 水和土壤养分等资源因子的空间再分配，对植被产 生直接作用(Cantón et al, 2004)。已有研究表明, 地 形因子对地表甲虫分布存在影响(杨贵军等, 2016; 杨益春等, 2017), 土壤理化性质对地表甲虫多样性 也存在重要作用(Thomas \& Marshall, 1999; 郭海滨 等, 2009; 娄巧哲等, 2011; 李岳诚等, 2014)。地表甲 虫在甲虫中占较大比例, 因此, 今后的研究应进一 步引入土壤与地形等因素, 将有助于更全面探究该 区域甲虫物种丰富度分布格局的潜在影响机制。

\section{参考文献}

Bai XS, Cai WZ, Nonnaizab (2013) Insects in Helan Mountain of Inner Mongolia. Inner Mongolia People’s Publishing House, Hohhot. (in Chinese) [白晓拴, 彩万志, 能乃扎布 (2013) 内蒙古贺兰山地区昆虫. 内蒙古人民出版社, 呼 和浩特.]

Bai Y, Xu SQ, Deng SF (2006) Cluster analysis on the distribution patterns of grasshopper in Shaanxi. Acta Zootaxonomica Sinica, 31, 18-24. (in Chinese with English abstract) [白义, 许升全, 邓素芳 (2006) 陕西蝗虫地理分布格局 的聚类分析. 动物分类学报, 31, 18-24.]

Cantón Y, Del Barrio G, Solé-Benet A, Lázaro R (2004) Topographic controls on the spatial distribution of ground cover in the Tabernas badlands of SE Spain. Catena, 55, 341-365.
Chen SB, Jiang GM, Ouyang ZY, Xu WH, Xiao Y (2011) Relative importance of water, energy, and heterogeneity in determining regional pteridophyte and seed plant richness in China. Journal of Systematics and Evolution, 49, 95-107.

Cox CB, Moore PD, Ladle R (2016) Biogeography: An Ecological and Evolutionary Approach. John Wiley \& Sons, Chichester.

Diniz-Filho JAF, Marco PD, Hawkins BA (2010) Defying the curse of ignorance: Perspectives in insect macroecology and conservation biogeography. Insect Conservation and Diversity, 3, 172-179.

Dong J, Kergoat GJ, Vicente N, Rahmadi C, Xu S, Robillard T (2018) Biogeographic patterns and diversification dynamics of the genus Cardiodactylus Saussure (Orthoptera, Grylloidea, Eneopterinae) in Southeast Asia. Molecular Phylogenetics and Evolution, 129, 1-14.

Feng JM, Zhu YY (2010) Geographical patterns of diversity of Gymnosperms in northwest Yunnan and their correlation with flora differentiation. Ecology and Environmental Sciences, 19, 830-835. (in Chinese with English abstract) [冯 建孟, 朱有勇 (2010) 滇西北地区裸子植物多样性的地 理分布格局及其与区系分化之间的关系. 生态环境学报, 19, 830-835.]

Gaston KJ (2000) Global patterns in biodiversity. Nature, 405, 220-227.

Gotelli NJ, Arnett AE (2000) Biogeographic effects of red fire ant invasion. Ecology Letters, 3, 257-261.

Green J, Bohannan BJM (2006) Spatial scaling of microbial biodiversity. Trends in Ecology and Evolution, 21, 501-507.

Guo HB, Li BP, Qiang S, Yang DX, Song L (2009) Insect community structure in relation to environmental factors on bermudagrass lawn. Journal of Nanjing Agricultural University, 32, 63-70. (in Chinese with English abstract) [郭海滨, 李保平, 强胜, 杨德金金, 宋琳 (2009) 狗牙根草坪昆虫群 落组成与环境因子相关性研究. 南京农业大学学报, 32, 63-70.]

Guo K, Qiao GX (2005) Study on geographical distributional pattern of the subfamily Hormaphidinae (Homoptera, Ormaphididae). Acta Zootaxonomica Sinica, 30, 252-256. (in Chinese with English abstract) [郭昆, 乔格侠 (2005) 扁蚜 亚科(同翅目，扁蚜科)蚜虫地理分布格局初探. 动物分类 学报, 30, 252-256.]

Hawkins BA (2001) Ecology's oldest pattern? Trends in Ecology \& Evolution, 16, 470.

Jaccard P (1912) The distribution of the flora in the alpine zone. New Phytologist, 11, 37-50.

Jia L (2014) Fauna and Distribution of Tenebrionid Beetles in Alxa Plateau (Coleoptera: Tenebrionoidea). PhD dissertation, Hebei University, Baoding. (in Chinese with English abstract) [贾龙 (2014) 阿拉善高原拟步甲区系与地理分 布(鞘翅目: 拟步甲总科). 博士学位论文, 河北大学, 保 定.]

Jiang ZG, Ji LQ (1999) Avian-mammalian species diversity in 
nine representative sites in China. Chinese Biodiversity, 7, 220-225. (in Chinese with English abstract) [蒋志刚, 纪力 强 (1999) 鸟兽物种多样性测度的 $G-F$ 指数方法. 生物多 样性, 7, 220-225.]

Li G, Shen ZH, Ying JS, Fang JY (2009) The spatial pattern of species richness and diversity centers of gymnosperm in China. Biodiversity Science, 17, 272-279. (in Chinese with English abstract) [李果, 沈泽昊, 应俊生, 方精云 (2009) 中国裸子植物物种丰富度空间格局与多样性中心. 生物 多样性, 17, 272-279.]

Li HR, Chen XS (2009) The fauna and biogeography of planhoppers (Hemiptera, Fulgoroidea, Delphacidae) in Guizhou. Journal of Mountain Agriculture and Biology, 28, 485-491. (in Chinese with English abstract) [李红荣, 陈祥盛 (2009) 贵州飞䖝科昆虫物种多样性及地理分布格局(半翅目, 蜡 蝉总科, 飞風科). 山地农业生物学报, 28, 485-491.]

Li YC, Zhang DZ, He DH (2014) Species diversity of grounddwelling beetles and its relationship with environmental factors in the artificial Caragana brushland of fixed sandy lands in Ningxia. Scientia Silvae Sinicae, 50, 109-117. (in Chinese with English abstract) [李岳诚, 张大治, 贺达汉 (2014) 荒漠景观固沙柠条林地地表甲虫多样性及其与环 境因子的关系. 林业科学, 50, 109-117.]

Liang CZ, Zhu ZY, Li ZG (2012) The Vegetation of Helan Mountain. Sunshine Publishing House, Yinchuan. (in Chinese) [梁存柱, 朱宗元, 李志刚 (2012) 贺兰山植被. 阳光出版社, 银川.]

Liu DF, Zhang ZX, Jiang GF, Zhang DY, Liu JW, Huo GM (2009) Molecular biogeography of some species of the Acrididae in China. Science Bulletin, 54, 756-764. (in Chinese with English abstract) [刘殿锋, 张志轩, 蒋国芳, 张大羽, 刘建文, 霍光明 (2009) 中国蝗科部分昆虫的分子生物 地理学分析. 科学通报, 54, 756-764.]

Lou QZ, Xu YC, Ma JH, Lü ZZ (2011) Diversity of grounddwelling beetles within the southern Gurbantunggut Desert and its relationship with environmental factors. Biodiversity Science, 19, 441-452. (in Chinese with English abstract) [娄 巧哲, 徐养诚, 马吉宏, 吕昭智 (2011) 古尔班通古特沙 漠南缘地表甲虫物种多样性及其与环境的关系. 生物多 样性, 19, 441-452.]

O’Brien EM (2006) Biological relativity to water-energy dynamics. Journal of Biogeography, 33, 1868-1888.

Qiao GX, Xu XQ, Qu YH, Zhang GX, Lei FM (2003) Species diversity and geographical distribution patterns of Drepanosiphidae in China. Acta Zootaxonomica Sinica, 28, 416-427. (in Chinese with English abstract) [乔格侠, 徐晓群, 屈延 华, 张广学, 雷富民 (2003) 中国斑蚜科物种多样性及地 理分布格局. 动物分类学报, 28, 416-427.]

Sanders NJ, Lessard JP, Fitzpatrick MC, Dunn RR (2007) Temperature, but not productivity or geometry, predicts elevational diversity gradients in ants across spatial grains. Global Ecology and Biogeography, 16, 640-649.

Schuldt A, Baruffol M, Böhnke M, Bruelheide H, Hädtle W,
Lang AC, Nadrowski K, von Oheimb G, Voigt W, Zhou HZ, Assmann T (2010) Tree diversity promotes insect herbivory in subtropical forests of south-east China. Journal of Ecology, 98, 917-926.

Shah DN, Tonkin JD, Haase P, Jähnig SC (2015) Latitudinal patterns and large-scale environmental determinants of stream insect richness across Europe. Limnologica, 55, 33-43.

Shen MW, Chen SB, Bi MJ, Chen WD, Zhou KX (2016) Relationships between geographic patterns of ant species richness and environmental factors in China. Acta Ecologica Sinica, 36, 7732-7739. (in Chinese with English abstract) [沈梦伟，陈圣宾，毕孟杰，陈文德，周可新 (2016) 中国 蚂蚁丰富度地理分布格局及其与环境因子的关系. 生态 学报, 36, 7732-7739.]

Thomas CFG, Marshall EJP (1999) Arthropod abundance and diversity in differently vegetated margins of arable fields. Agriculture, Ecosystems \& Environment, 72, 131-144.

Turner JR (2004) Explaining the global biodiversity gradient: Energy, area, history and natural selection. Basic and Applied Ecology, 5, 435-448.

Wang JM, Cui PJ, Zhong YM, Li JW, Chu JM (2019) Biogeographic patterns and environmental interpretation of plant regional species richness in Alxa Plateau of northern China. Journal of Beijing Forestry University, 41(3), 14-23. (in Chinese with English abstract) [王健铭, 崔盼杰, 钟悦鸣, 李景文, 褚建民 (2019) 阿拉善高原植物区域物种丰富 度格局及其环境解释. 北京林业大学学报, 41(3), 14-23.]

Wang W, Pei H, Liang CZ, Zhu ZY, Wang YL, Zhang T (2004) The diversity and spatial distribution of plant communities in the Helan Mountains. Acta Phytoecologica Sinica, 28, 361-368. (in Chinese with English abstract) [王炜, 裴浩, 梁存柱, 朱宗元, 王永利, 张蹈 (2004) 贺兰山植 物群落类型多样性及其空间分异. 植物生态学报, 28, 361-368.]

Wang XM (2011) Comprehensive Scientific Investigation Report on Helan Mountain National Nature Reserve in Ningxia. Sunshine Publishing House, Yinchuan. (in Chinese) [王小明 (2011) 宁夏贺兰山国家级自然保护区综合 科学考察报告. 阳光出版社, 银川.]

Wang XP, Yang GJ (2010) Insects of Helan Mountain in Ningxia. Ningxia People's Publishing House, Yinchuan. (in Chinese) [王新谱, 杨贵军 (2010) 宁夏贺兰山昆虫. 宁夏 人民出版社, 银川.]

Wang ZH, Tang ZY, Fang JY (2009) The species-energy hypothesis as a mechanism for species richness patterns. Biodiversity Science, 17, 613-624. (in Chinese with English abstract) [王志恒, 唐志尧, 方精云 (2009) 物种多样性地 理格局的能量假说. 生物多样性, 17, 613-624.]

Xu SQ, Zheng ZM, Li HH (2004) Cluster analysis on the distribution patterns of grasshopper in Ningxia. Zoological Research, 25, 96-104. (in Chinese with English abstract) [许 升全, 郑哲民, 李后魂 (2004) 宁夏蝗虫地理分布格局的 聚类分析. 动物学研究, 25, 96-104.] 
Yang GJ, Jia L, Zhang JY, Yu YZ (2016) Distribution of darkling beetles and its relationships with topography in Helan Mountain, Ningxia. Journal of Environmental Entomology, 38, 77-86. (in Chinese with English abstract) [杨贵 军, 贾龙, 张建英, 于有志 (2016) 宁夏贺兰山拟步甲科 昆虫分布与地形的关系. 环境昆虫学报, 38, 77-86.]

Yang YC, Yang GJ, Wang J (2017) Effects of topographic factors on the distribution pattern of carabid species diversity in the Helan Mountains, northwestern China. Acta Entomologica Sinica, 60, 1060-1073. (in Chinese with English abstract) [杨益春, 杨贵军, 王杰 (2017) 地形对贺兰山步甲 群落物种多样性分布格局的影响. 昆虫学报, 60, 1060-1073.]

Zhang K, Lin SL, Ji YQ, Yang CX, Wang XY, Yang CY, Wang HS, Jiang HD, Harrison RD, Yu DW (2016) Plant diversity accurately predicts insect diversity in two tropical landscapes. Molecular Ecology, 25, 4407-4419.

Zhang RZ (2011) Zoogeography of China. Science Press, Beijing. (in Chinese) [张荣祖 (2011) 中国动物地理. 科学 出版社, 北京.]

Zhang Y, Feng G (2018) Distribution pattern and mechanism of insect species diversity in Inner Mongolia. Biodiversity Science, 26, 701-706. (in Chinese with English abstract) [张
宇, 冯刚 (2018) 内蒙古昆虫物种多样性分布格局及其 机制. 生物多样性, 26, 701-706.]

Zhang ZG, Jiang X, Zhang MB, Xu ZC, Deng DM, You YF (2018) Geographical distribution pattern of Issidae (Hemiptera: Fulgromorpha) from China. Journal of Jinggangshan University (Natural Science), 39, 97-103. (in Chinese with English abstract) [张争光, 江西, 张梦博, 徐镇超, 邓德 美, 尤云菲 (2018) 中国漂蜡蝉科(半翅目: 蜡蝉总科)昆 虫的地理分布格局. 井冈山大学学报(自然科学版), 39, 97-103.]

Zhao HG, Liu CY, Wang F, Wang JQ, Li Q, Yao YM (2007) Uplift time and its evolution of Helan Mountain. Science China (D: Geoscience), 66, 185-192. (in Chinese with English abstract) [赵红格, 刘池洋, 王锋, 王建强, 李琼, 姚 亚明 (2007) 贺兰山隆升时限及其演化. 中国科学( D辑: 地球科学), 66, 185-192.]

Zobel M (1997) The relative role of species pools in determining plant species richness: An alternative explanation of species coexistence? Trends in Ecology \& Evolution, 12, 266-269.

\section{附录 Supplementary Material}

附录 1 贺兰山甲虫物种名录

Appendix 1 List of beetle species in Helan Mountain http://www.biodiversity-science.net/fileup/PDF/2019184-1.pdf 